\title{
A EXPERIÊNCIA DOCENTE NO ENSINO DE HISTÓRIA DO LIVRO E DAS BIBLIOTECAS NA UNIVERSIDADE FEDERAL DO PARÁ (UFPA)
}

\author{
LA EXPERIENCIA DOCENTE EN LA ENSEÑANZA DE LA \\ HISTORIA DEL LIBRO Y DE LAS BIBLIOTECAS EN LA \\ UNIVERSIDADE FEDERAL DO PARÁ (UFPA)
}

\author{
Rubens da Silva Ferreira*
}

\begin{abstract}
RESUMO
Introdução: $O$ trabalho relata a experiência docente na disciplina História do Livro e das Bibliotecas do curso de Biblioteconomia da Universidade Federal do Pará (UFPA). Presente no currículo do curso desde 1963, essa disciplina é basilar para a formação dos futuros bibliotecários, pois trabalha com três importantes elementos que são dinâmicos na história da profissão: o suporte (o livro), a instituição (a biblioteca) e o profissional (o bibliotecário).

Objetivo: Reúne, sistematiza e socializa estratégias utilizadas no processo ensino-aprendizagem no contexto da disciplina História do Livro e das Bibliotecas.
\end{abstract}

Metodologia: Ao longo de dois anos (2010-2012), para além das aulas expositivas, o processo ensino-aprendizagem foi dinamizado com a realização de visitas técnicas, a introdução de textos para leitura complementar em língua estrangeira e a construção de um site com o auxílio de monitores, a fim de associar as novidades tecnológicas a uma disciplina em que os elementos "livro" e "biblioteca" suscitam, nos discentes, a ideia de tradição.

Resultados: A estratégia usada mostra ser satisfatória quanto ao desempenho dos alunos. O principal desafio reside na necessidade do desenvolvimento das competências de leitura e de escrita, aspectos essenciais a serem considerados para uma formação profissional qualitativa, sobretudo porque os futuros egressos atuarão na área da documentação/informação.

Conclusões: Os aspectos negativos da experiência: (1) as dificuldades de alunos das turmas noturnas para participarem de visitas técnicas; e (2) os estágios acumulados pelos alunos que afetam o desempenho na disciplina. Os aspectos positivos da experiência: (1) a melhora da habilidade de escrita; (2) o crescimento de interesse pela produção científica; (3) o crescimento de interesse por cursos de idioma; (4) o contato dos monitores de classe com a prática docente; e (5) uma melhor assimilação dos conteúdos trabalhados na disciplina.

* Doutorando do Programa de Pós-graduação em Ciência da Informação Universidade Federal do Rio de Janeiro (UFRJ). Professor da Faculdade de Biblioteconomia da Universidade Federal do Pará (UFPA). E-mail: rubenspa@yahoo.com 
Palavras-chave: Educação superior. Biblioteconomia. História do livro e das bibliotecas. Universidade Federal do Pará. Faculdade de biblioteconomia.

\section{INTRODUÇÃO}

[...] quanta doctrinae commoditas sit in libris, quam facilis, quam arcana. Quam tuto libris humanae ignorantiae paupertatem sine verecundia denudamus![...] (Ricardo de Bury, Philobiblon, 1345).

A matriz curricular dos cursos de Biblioteconomia no Brasil traz uma disciplina que desempenha papel fundamental na formação dos futuros bibliotecários. Trata-se daquela que se convencionou denominar História do Livro e das Bibliotecas. Em razão de sua existência histórica - o que no curso de Biblioteconomia da Universidade Federal do Pará (UFPA) remonta aos anos de 1963 (BECKMANN, 2007) -, compreender os aspectos que a mantém até os dias atuais torna-se necessário pelo caráter teórico e conceitual orientador quanto às origens das bibliotecas, ao aparecimento do bibliotecário e das mudanças pelas quais passaram os diferentes suportes de informação diante de certos determinantes políticos, econômicos, culturais e sociais. De igual modo, por meio dela é possível aproximar os alunos dos princípios que lançaram as bases de uma profissão hoje consolidada, que evoluiu da organização e da guarda de documentos para a complexa gestão de bibliotecas e de recursos humanos, materiais e imateriais, mobilizando diferentes saberes e práticas na oferta de serviços à sociedade, pretendendo, assim, cumprir sua função finalística, isto é, a mediação no acesso à informação e ao conhecimento que as pessoas demandam em suas atividades laborais, instrucionais e recreativas.

Dessa maneira, olhar a trajetória de um suporte (o livro), de uma instituição (a biblioteca) e de um profissional (o bibliotecário) em sua dinâmica ao longo de toda a experiência civilizatória da espécie humana significa, entre outras coisas, buscar as raízes do que se pode chamar de uma identidade bibliotecária. É por meio da disciplina em foco que se 
pode reconstituir o caminho que justifica a existência social do bibliotecário e, deste modo, conhecer os acontecimentos históricos que contribuíram para legitimar tal profissão. Um percurso direcionado, a princípio, pelos esforços de preservar os feitos da humanidade registrados na forma de imagens e/ou de texto escrito, gravado em folhas soltas que, mais tarde, foram unidas entre si e envolvidas por uma capa formando o códice, documento medieval do qual se originou o livro no formato em que é amplamente conhecido (LYONS, 2011; MARTINS, 2002). Em um segundo momento, o aumento da produção do livro com a expansão das universidades desde o século XIII e, principalmente, com o advento da imprensa a partir de 1450 (LYONS, 2011; MARTINS, 2002; MCNEELY; WOLVERTON, 2013), transformaram drasticamente o cotidiano do trabalho nas bibliotecas. Progressivamente as sociedades modernas começaram a exigir pessoal cada vez mais especializado para se dedicar à gestão das coleções bibliográficas, culminando na criação do primeiro curso de Biblioteconomia no século XIX, precisamente na École des Chartes, em Paris.

Em face desse panorama histórico sobre o qual se desenvolvem três elementos indissociáveis, ou seja, o livro, a biblioteca e o bibliotecário, há que se considerar o contato dos alunos de Biblioteconomia com a disciplina História do Livro e das Bibliotecas como aquele capaz de estabelecer, ou não, a identificação primeira com a profissão buscada na universidade, resultando daí, a decisão de prosseguir ou de desistir do curso. Esse peso implica responsabilidade ao docente para com os conteúdos ministrados, os métodos escolhidos, assim como a importância do desempenho didático diante de turmas cada vez mais familiarizadas às Tecnologias de Informação e Comunicação (TIC). Nesse sentido, a missão de falar sobre um suporte de escrita impresso, tido pelos mais afoitos "tecnoadmiradores" como ferramenta obsoleta de mediação da informação e do conhecimento se torna desafiadora, isso porque os jovens nascidos a partir dos anos de 
1990 começam a assumir a responsabilidade pela autoinstrução, algo que é viabilizado pela multiplicidade das fontes e dos conteúdos existentes na Internet, experiência esta representada pelo que autores como Assmann (1998) se referem como "sociedade aprendente". Assim, este trabalho tem por objetivo reunir, sistematizar e socializar informações acerca da experiência vivenciada na relação professor/aluno no contexto da disciplina História do Livro e das Bibliotecas, destacando os procedimentos de ensino, o processo de avaliação, os fatores positivos e os desafios que se impõe ao fazer docente, tal como apresentado a seguir.

\section{SOBRE AS TURMAS E $O$ PROCESSO ENSINO- APRENDIZAGEM}

No Projeto Político-Pedagógico do curso de Biblioteconomia da UFPA, em vigor desde 2009, a disciplina História do Livro e das Bibliotecas integra o eixo temático Fundamentos Teóricos da Biblioteconomia, compreendendo uma carga horária total de $64 \mathrm{~h}$ (UNIVERSIDADE FEDERAL DO PARÁ, 2009b). Comparando o programa atual ao do currículo de 1963, além da carga horária não se verifica alterações drásticas de conteúdo. A experiência na disciplina tem mostrado que alguns elementos do programa atual correspondem a desdobramentos de seu predecessor, a exemplo daqueles que se referem à imprensa, ao seu aperfeiçoador, aos tipógrafos renomados, à difusão e ao desenvolvimento técnico e tecnológico pelos quais ela atravessou na produção do livro impresso.

Por fornecer uma base teórica e conceitual, capaz de sustentar não somente uma formação técnica (inspirada na escola americana) como também erudita (inspirada na escola francesa), ambas necessárias aos futuros bibliotecários, a disciplina é regularmente ofertada aos recém-ingressos no primeiro semestre de cada ano letivo. Desse modo, entre 2010 e 2012, seis turmas cursaram História do Livro 
e das Bibliotecas, tal como aparecem relacionadas na Tabela 1, na qual os alunos são distribuídos por ano, turno e sexo. Cabe observar nessa tabela que, ao longo de dois anos, do montante de 198 discentes matriculados, $26 \%$ são do sexo masculino e $74 \%$ são do sexo feminino, o que reafirma uma tendência que se mantém, a da maior procura de mulheres pela Biblioteconomia desde a primeira metade do século $\mathrm{XX}$, dado esse que contrasta com a presença hegemônica dos homens na profissão de bibliotecário no século anterior.

Quanto a uma problemática de gênero, é notório, no Brasil, o aumento discreto na procura de homens pela profissão de bibliotecário, o que tem início a partir dos anos de 1990, quando as TIC são mais intensamente introduzidas no espaço das bibliotecas. A respeito dessa procura é interessante registrar o comentário do Dr. Gustavo Saldanha, proferido em agosto de 2013, por ocasião da qualificação do projeto apresentado por Elinielle Pinto Borges ao Programa de Pós-Graduação em Ciência da Informação do Instituto Brasileiro de Informação em Ciência e Tecnologia, em convênio com a Universidade Federal do Rio de Janeiro (PPGCI-IBICT/UFRJ), em que propôs estudar a presença da mulher na ciência. Nessa direção, o professor Gustavo bem observava que tal crescimento se deve ao discurso de racionalidade subjacente às novas tecnologias. Um discurso impregnado de valores próprios das sociedades de tradição patriarcal, tal como é a brasileira, na qual a figura masculina ainda se impõe muito fortemente em relação ao gênero feminino. Assim, se o caráter racional está associado culturalmente ao universo masculino e, em função disso, os homens detêm a primazia na produção do conhecimento científico e tecnológico, torna-se fácil entender porque as TIC funcionam como elementos que os atraem para o trabalho nas bibliotecas.

Todavia, retomando as turmas com as quais se trabalhou entre 2010-2012, há que se falar sobre a condução das atividades de ensinoaprendizagem propriamente ditas. 
De acordo com o programa da disciplina apresentado aos alunos, as aulas foram conduzidas de maneira expositiva, com o professor estimulando a participação, procurando estabelecer relações entre os conteúdos abordados com base na bibliografia obrigatória, e conectando os temas de História e de Geografia com os quais as turmas já tiveram contato em seu processo de escolarização. Ao final, por vezes, as aulas eram seguidas por leituras complementares, realizadas em sala e em grupo, ou em contextos extraclasse, tendo por objetivo potencializar a assimilação de informações e de conhecimentos sobre os acontecimentos históricos que elevaram o livro ao status de símbolo do conhecimento nas sociedades letradas.

Por assimilação da informação, deve-se entender aqui o ato de interpretação individual, que corresponde a um processo que se sucede em um tempo não linear de reflexão entre as experiências do passado e as expectativas do futuro, resultando em uma consciência capaz de criar as condições para que os indivíduos possam aceitar, ou não, as informações com as quais entram em contato na vida cotidiana (BARRETO, 1994, 2002). Assim, em relação às leituras de caráter extraclasse, não apenas textos em língua portuguesa foram utilizados como também em inglês e/ou espanhol. Mesmo que os discentes não dominassem essas línguas, eles eram orientados quanto ao uso de dicionários e de ferramentas tecnológicas disponíveis na Internet, a fim de que realizassem ao menos uma leitura contextual mínima, e, assim, participassem das discussões fomentadas em sala de aula. Atividades desse tipo requerem que os textos sejam fornecidos sempre com antecedência, permitindo aos alunos trabalharem a leitura de forma gradual e produtiva. 
Tabela 1 - Composição das turmas da disciplina História do Livro e das

Bibliotecas quanto ao sexo (2010-2012)

\begin{tabular}{l|c|c|c|c|c|c|c|c|c|c|c|c|c|c|}
\hline \multicolumn{9}{|c}{ Turmas de 2010 } & \multicolumn{3}{|c|}{ Turmas de 2011 } & \multicolumn{3}{|c|}{ Turmas de 2012 } \\
\hline Turno & Manhã & Noite & Subtotais & $\%$ & Manhã & Noite & Subtotais & $\%$ & Manhã & Noite & Subtotais & $\%$ & Totais & \% \\
\hline Homens & 5 & 9 & 14 & 25 & 9 & 10 & 19 & 30 & 7 & 12 & 19 & 24 & 52 & 26 \\
\hline Mulheres & 25 & 17 & 42 & 75 & 23 & 22 & 45 & 70 & 33 & 26 & 59 & 76 & 146 & 74 \\
\hline Totais & 30 & 26 & 56 & 100 & 32 & 32 & 64 & 100 & 40 & 38 & 78 & 100 & 198 & 100 \\
\hline
\end{tabular}

Fonte: Folhas de aproveitamento da disciplina História do Livro e das Bibliotecas, Sistema de Controle Acadêmico - 2010-2012 (UFPA, 2009).

Ainda em relação aos textos em língua estrangeira utilizados na disciplina, eles foram atualizados a cada nova turma. Em 2012, por exemplo, adotou-se a introdução do livro Monasteries: Places of spirituality and seclusion around the world, de Hattstein (2010), por meio do qual se procurou compreender a vida de reclusão dos monges na Idade Média que, entre outras coisas, dedicavam-se à atividade de copistas no scriptorium, esse tipo de salão comum nos mosteiros onde foram traduzidos muitos manuscritos do grego para o latim, antes mesmo de serem impressos em línguas vernáculas no período pós Gutemberg. Já com as turmas de 2011 foi utilizado o artigo de Gil Paneque (2010), El alto destino de los escribas, publicado na revista Historia y Vida. Com base nesse texto aprofundou-se a aula sobre escrita ao trazer elementos relacionados ao papel social de um determinado segmento de pessoas, quase que exclusivamente do sexo masculino, encarregado de uma função altamente especializada: o registro das atividades administrativas, científicas e religiosas na Antiguidade, precisamente no Egito.

Foi assim que o estímulo ao contato com material em outros idiomas acabou por motivar alguns discentes a buscarem cursos livres de inglês ou de espanhol oferecidos pela UFPA, o que se sabe conforme os relatos recebidos durante e/ou após a conclusão da disciplina. Uma prática, aliás, que tende a repercutir positivamente na vida daqueles que optarem no futuro pela formação continuada na pósgraduação, qual seja em cursos de especialização, de mestrado ou de doutorado para os quais se pressupõe a maior utilização de textos em língua estrangeira. 
Leituras complementares de textos em língua portuguesa também foram recomendadas. Nesses casos, solicitava-se a elaboração de sínteses (resenhas) com o objetivo de estimular os alunos a identificarem os argumentos centrais e os conceitos presentes no material selecionado, resultando em um exercício de escrita sobre o que era lido. Inclusive por meio dessa atividade foi possível constatar que embora alguns tenham produzido observações e reflexões interessantes, outros, porém, limitaram-se a reproduções textuais, às vezes com fragmentos obtidos inteiramente da Internet, o que revela uma prática a ser enfrentada no ensino de graduação não só na UFPA como em outras universidades públicas e particulares no Brasil. Por isso defende-se aqui a oferta regular de cursos online ou presenciais gratuitos de produção de texto no âmbito dessas instituições, a fim de instrumentalizar os discentes para uma prática escrita mais fluída e qualitativa. Isso porque o domínio dessa competência tem relação direta com o desempenho profissional dos egressos no futuro, inclusive na prestação de concursos públicos, na produção de relatórios técnicocientíficos, de correspondências oficiais, de pareceres, e mesmo na produção científica em Biblioteconomia e/ou Ciência da Informação, a qual precisa ser estimulada ainda no ensino de graduação, notadamente com o acompanhamento e a orientação dos professores.

Além dos textos de que se falou acima, outros recursos didáticos foram utilizados, variando conforme o tema trabalhado em sala de aula. llustrações, vídeos postados no Youtube e trechos de filmes comerciais também foram empregados para auxiliar o processo ensinoaprendizagem na disciplina. Embora ler seja atividade sine qua non na construção do conhecimento técnico e científico, em História do Livro e das Bibliotecas a experiência do olhar também se mostra fundamental. Em razão disso, o uso de slides por meio do Datashow permite ver exatamente no sentido antropológico empregado por Bronislaw Kaspar Malinowski, segundo informa Samain (1995) - personagens, formas e cores de realidades passadas e presentes. Enfim, detalhes que só 
podem ser capitados pelos olhos por meio da fotografia e de outros registros imagéticos, agora multiplicados com a popularização das tecnologias que permitem sua (re)produção. Em tempos de uma sociedade da imagem é possível pensar, inclusive, em atividades de aprendizagem que estimulem os discentes a explorar esses recursos, não só como meros leitores/espectadores, mas também como produtores de fotografias e de vídeos nos quais possam trabalhar os conteúdos da disciplina, a exemplo das experiências autônomas disseminadas no Youtube ou nos muitos blogs educativos disponíveis na Internet.

Ainda sobre o uso de material audiovisual, o recurso aos vídeos comerciais ocorreu quando necessário e de modo muito pontual, exibindo filmes que se relacionavam aos temas das aulas. Entre esses recursos foram exibidos títulos que se tornaram emblemáticos na Biblioteconomia, tais como $O$ nome da rosa (1986), A guerra do fogo (1981), Fahrenheit 451 (1966) e Alexandria (2009). Quanto às imagens estáticas utilizadas, parte delas constituiu-se de fotografias produzidas pelo professor, precipuamente a partir de visitas realizadas em museus e bibliotecas do Brasil e do exterior. Os livros acorrentados, as tabuinhas de argila com seus registros cuneiformes, as placas de mármore com escrita monumental, os papiros egípcios e os livros de horas, por exemplo, não somente foram mostrados por meio de fotos como estas também foram cedidas aos trabalhos elaborados pelos discentes, seja para os seminários apresentados em sala de aula, na elaboração de artigos ou nas comunicações em eventos técnico-científicos, todavia, sempre respeitando os créditos da autoria. Como se pode ver, fotografias e vídeos são recursos educativos da maior importância, especialmente em uma disciplina cuja experiência visual faz parte do processo de construção do conhecimento sobre o livro, as bibliotecas e os bibliotecários, de maneira que os alunos possam pensar sobre o que foram esses elementos no passado, o que representam hoje e, deste 
modo, especular sobre o que serão em um futuro de tendência cada vez mais digital.

A experiência docente em História do Livro e das Bibliotecas nesse período também foi enriquecida com as relações aluno/professor que se construíram na monitoria. Em 2012, por meio do Edital no 01/2012, foi possível contar com a participação três discentes como monitores da disciplina. Atualmente graduados e exercendo a profissão em bibliotecas universitárias, esses jovens contribuíram com o processo ensino-aprendizado de diferentes formas. Entre essas se tem a construção de um site no qual reuniram recursos textuais, imagéticos e audiovisuais trabalhados em sala de aula e sujeitos a atualizações a cada oferta da disciplina no futuro, inclusive recebendo contribuições dos próprios discentes. Nessa ferramenta planejada e desenvolvida pelos monitores com a supervisão do professor, é possível visualizar o programa da disciplina, fotografias das turmas, relação das instituições que acolheram as visitas técnicas programadas, bem como uma seleção de textos e de vídeos relacionados à disciplina que se encontravam dispersos na Internet.

Quanto aos conteúdos da disciplina, os monitores também foram orientados a elaborar boxes, ou seja, a realizar inserções pontuais nas aulas expositivas. O box corresponde a um recurso editorial muito utilizado em livros e periódicos. É, em si, um texto explicativo e breve, delimitado por uma estrutura geométrica, geralmente um quadrado, um retângulo ou um círculo que se relaciona ao texto principal. Essa atividade didática, com duração máxima de 15 minutos, tinha como finalidade a explanação de assuntos relacionados ao tema central da aula. Com efeito, era a possibilidade que se oferecia aos monitores para o estudo de um determinado conteúdo - de caráter complementar sobre o qual explanavam para os alunos em um exercício preparatório ao trabalho docente. Foi assim que nas aulas sobre bibliotecas medievais eles discorreram, por exemplo, sobre o tema das iluminuras. Apesar do nervosismo que normalmente se impõe ao ato de falar em 
público, tratava-se de um momento de aprendizado da maior importância para aqueles que desejavam seguir a carreira no magistério superior, o que recentemente se tornou realidade com um deles, atualmente engajado na condição de professor substituto na Faculdade de Biblioteconomia (FABIB/UFPA).

Além das aulas expositivas, uma parte do programa foi dedicada à realização de visitas técnicas. Desde 2010 essa atividade é conduzida em dois locais distintos, podendo ser alternados a cada ano, ou não, conforme a disponibilidade desses espaços e dos(as) bibliotecários(as) para o acolhimento dos alunos. Esses locais correspondem à Seção de Obras Raras da Biblioteca Central da UFPA e à Biblioteca Fran Pacheco, do Grêmio Literário e Recreativo Português (GLRP), que em 2012 receberam uma turma matutina de ingressantes, conforme registram as Figuras 1 e 2 . O deslocamento da sala de aula para esses espaços tem sido revelador quanto à necessidade dos primeiros contatos dos alunos com o ambiente das bibliotecas, com as coleções que elas abrigam e com o léxico profissional, possibilitando, dessa maneira, o exercício de um olhar agora diferenciado, orientado pelo professor e pelos monitores para detalhes técnicos até então desconhecidos. Um modo de olhar que, como bem ensina Oliveira (1996), faz parte do disciplinamento acadêmico (por isso se cursam disciplinas) pelo qual os universitários são sensibilizados para perceberem o mundo, a realidade, os seres, as ideias e os objetos à luz das teorias e dos conceitos adquiridos ao longo da vivência construída na universidade.

A possibilidade de ver e de tocar obras produzidas entre os séculos XVI e XIX, parte delas ainda revestida por encadernações originais, ilustradas com técnicas que variam da xilogravura à litogravura, e, além disso, sentir a ambiência desses espaços reservados à pesquisa e aos estudos históricos, portanto, frequentados por usuários com necessidades informacionais muito peculiares, contribuiu para a identificação, ou não, dos alunos com o curso de 
Biblioteconomia. Após visitar essas bibliotecas, as turmas se mostraram mais confiantes na escolha da profissão, o que se evidenciou tanto pelas reações e pelas verbalizações, quanto pelos relatórios de visita técnica, elaborados pelos discentes imediatamente após a realização da atividade. Para alunos que começam a se adaptar ou já se familiarizaram aos e-books e às buscas no Google, talvez esse momento represente uma (re)descoberta da biblioteca em sua função educativa, informativa e cultural, do livro, em sua tradição impressa, bem como do profissional, essa pessoa que trabalha nesses espaços para que os conteúdos estejam em condições de acesso e de uso. Enfim, uma atividade da qual a disciplina não pode prescindir pelas experiências cognitivas e afetivas que oferece às turmas e ao próprio docente.

Figura 1 - À esquerda, registro fotográfico de visita técnica da turma matutina de 2012 à Seção de Obras Raras de Biblioteca Central da UFPA.

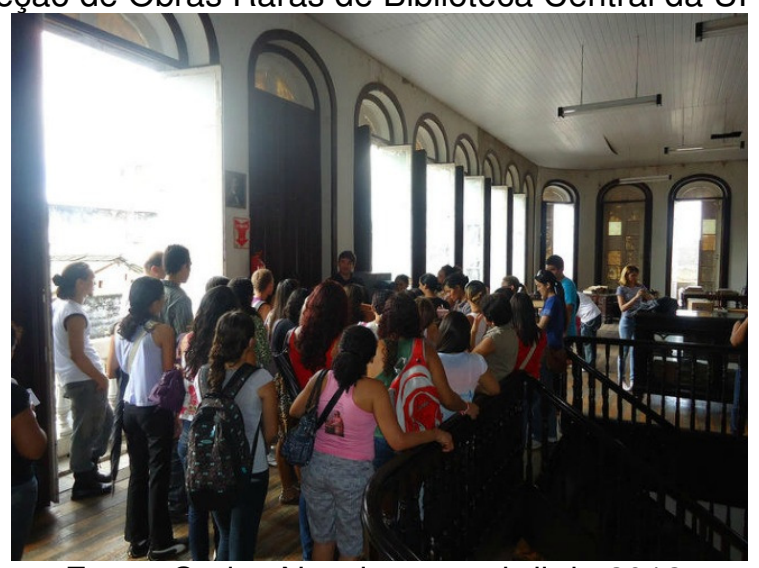

Fotos: Carlos Nascimento, abril de 2012. Fonte: Autora. 
Figura 2 - À direita, registro fotográfico da visita técnica da turma matutina de 2012 à Biblioteca Fran Pacheco do GLRP.

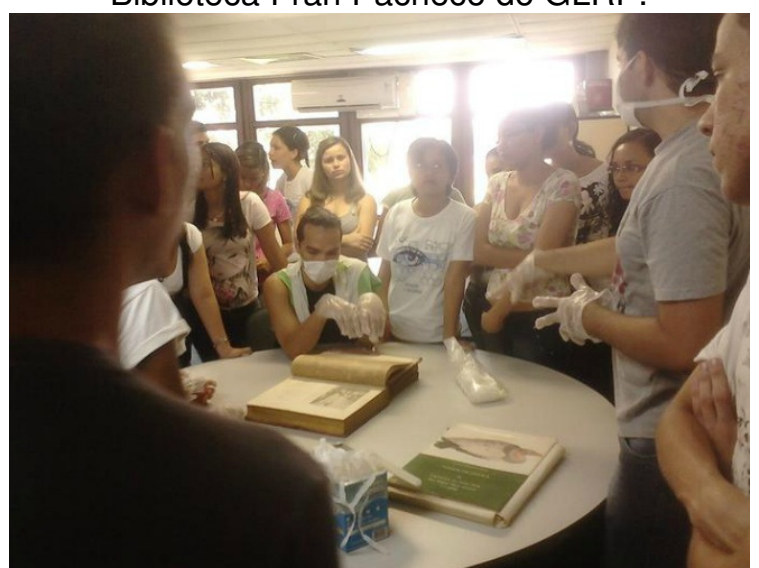

Fotos: Carlos Nascimento, abril de 2012.

Fonte: Autora.

Eventualmente outras atividades complementares foram agregadas à disciplina. Ao longo desses anos tem-se observado que quanto maior for a predisposição das turmas para interagir com discursos que estão para além dos conteúdos dos livros técnicos, dos artigos de periódicos científicos e do que é falado pelo docente em sala de aula, maior será o rendimento no aprendizado dos alunos. Foi nesse sentido que, em sala de aula, a turma de 2012 do período noturno assistiu a comunicação da arqueóloga Ivone Bezerra sobre a experiência dela com o software Osteoware, tal como registram as Figuras 3 e 4 . Esse programa destina-se ao inventariamento de coleções osteológicas, sendo distribuído de forma gratuita pelo Smithsonian Institution. O objetivo da atividade consistiu em mostrar aos alunos as formas automatizadas de organização de documentos, neste caso específico, ossos, procurando identificar, explicar e discutir conceitos com os quais as turmas entrarão em contato ao longo da formação universitária, tais como inventário, fontes de informação, bases de dados, catalogação, indexação, recuperação da informação e outros. 
Figura 3 - Na foto à esquerda, em pé, a arqueóloga Ivone Bezerra fala aos alunos de Biblioteconomia da turma de 2012, noite, sobre o software Osteoware, utilizado por ela durante o mestrado em Evolução e Biologia Humanas, realizado na Universidade de Coimbra, Portugal.

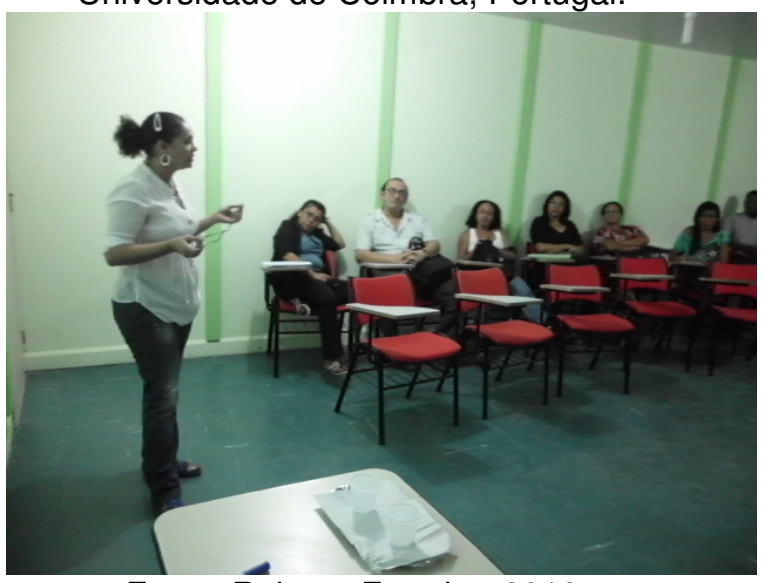

Fotos: Rubens Ferreira, 2012.

Fonte: Autora.

Figura 4 - Na foto à direita, tem-se uma vista dos alunos que se dispuseram gentilmente a participar de uma atividade promovida fora dos dias reservados à disciplina.

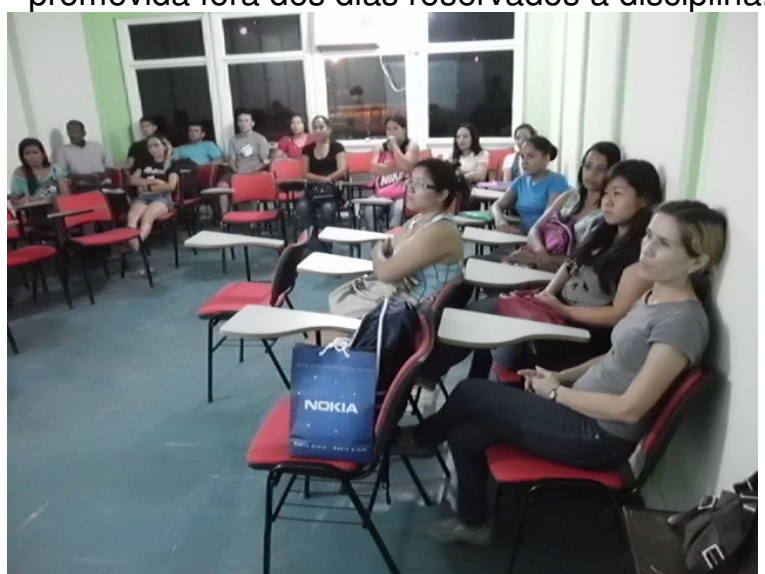

Fotos: Rubens Ferreira, 2012.

Fonte: Autora.

Quanto ao processo de avaliação da disciplina, as turmas experimentaram três atividades distintas. Desde 2010 a primeira verificação de aprendizagem se dá na forma de prova escrita, que consiste na elaboração de um texto dissertativo sobre os temas abordados na primeira unidade do programa. A segunda e a terceira avaliações, por sua vez, têm variado entre a realização de seminários para o exercício da expressão oral e do trabalho colaborativo, e a 
produção de artigos como estímulo à produção acadêmica. Em 2012, embora na avaliação das turmas de ingressantes tenha sido prevista a produção de artigos, em função da greve dos professores universitários a atividade não pôde ser executada, sobretudo porque um trabalho dessa natureza exige o acompanhamento sistemático do docente, seja por se tratarem de alunos recém-chegados à universidade, seja para evitar o plágio acadêmico. Assim, com as turmas de 2010 e 2012 foram adotados seminários sobre os temas da segunda unidade da disciplina. Já em 2011, os alunos puderam dedicar-se à elaboração de artigos sobre as obras dos viajantes naturalistas que passaram pela Amazônia brasileira entre os séculos XVII e XIX, procurando focar o papel do livro na comunicação científica, portanto, na circulação da informação e do conhecimento nos domínios da ciência, mas antes do aparecimento da Internet.

Dentre os artigos elaborados pelas turmas de 2011, merece destacar o das discentes Josiane Maciel, Suelene Santana e Paula Stephanie. Com o título "Alexandre Rodrigues Ferreira: um naturalista brasileiro produzindo informação sobre a Amazônia e o Centro-Oeste (1783-1792)", o trabalho foi apresentado, premiado e publicado nos Anais do Encontro Regional dos Estudantes de Biblioteconomia, Documentação, Ciência e Gestão da Informação, realizado em 2011, na cidade de Cariri (CE). Decerto, um reconhecimento da dedicação das alunas no primeiro trabalho produzido na forma de artigo e que se tornou um incentivo aos estudos e, principalmente, à produção científica ao longo do ensino de graduação.

Em relação ao desempenho global das turmas na disciplina História do Livro e das Bibliotecas no período 2010-2012, este pode ser medido pelos conceitos finais, que aparecem arrolados na Tabela 2, representados segundo determina o Regimento Geral da UFPA (2009a), em seu Capítulo IV, que trata sobre os conceitos de avaliação. Nessa tabela nota-se que os alunos matutinos de 2010, no geral, apresentam o melhor aproveitamento na disciplina, com 100\% das aprovações, 
distribuídas entre conceitos Excelente (43\%) e Bom (57\%). No período noturno foram aprovados $84 \%$ dos discentes, sendo $27 \%$ com Excelente, $46 \%$ com Bom e 1\% com Regular. Dessa mesma turma, 8\% foram reprovados e outros $8 \%$ abandonaram a disciplina. Os discentes de 2011, do período noturno, aparecem com o segundo melhor desempenho. Entre eles, 44\% foram aprovados com Excelente, $41 \%$ com Bom e $9 \%$ com Regular, registrando-se, ainda, uma reprovação (3\%) e um abandono na disciplina (3\%). Ao se olhar o quadro geral, a turma matutina de 2011 também se destaca na disciplina. Assim, dos 32 alunos matriculados, 32\% foram aprovados com Excelente, 53\% com Bom, $6 \%$ com Regular, havendo entre eles uma reprovação (3\%) e dois abandonos (6\%).

Ainda sobre a avaliação, importa observar que no ano de 2012 o curso de Biblioteconomia da UFPA teve sua oferta ampliada pelo Programa de Apoio a Planos de Reestruturação e Expansão das Universidades Federais (REUNI), passando de uma oferta de 60 vagas anuais para 80 ao ano. Esse Programa do governo federal foi instituído pelo Decreto n. 6.096/2007 (BRASIL, 2007), tendo como objetivo ampliar a expansão do ensino superior no país, no que se incluiu o aumento do número de vagas. O REUNI foi concluído exatamente no ano de 2012, quando duas turmas ingressaram no curso de Biblioteconomia da UFPA. Das vagas ampliadas, metade foi destinada ao período matutino e, outra, ao período noturno.

Esse incremento no número de vagas tem representado um desafio não só do ponto de vista da gestão da Faculdade, dadas as limitações dos recursos financeiros, pedagógicos e humanos, por certo uma situação enfrentada em outras universidades federais no país. Incremento esse que acabou por impactar inclusive na capacidade de lotação das salas de aula e do laboratório de informática, espaços que precisaram passar por duas recentes reformas para receber os novos alunos. Além da gestão, a ampliação das turmas tornou-se também um desafio da perspectiva do ensino, precisamente no processo de 
planejamento e de execução do trabalho docente, sobretudo na avaliação e no acompanhamento sistemático do desempenho de turmas agora mais numerosas. É assim que a questão das novas vagas impõe ao professor (re)pensar, (re)avaliar, (re)planejar e atualizar constantemente as estratégias de ensino-aprendizagem para lidar com uma realidade nova, e que apesar de desafiadora se mostra também estimulante quanto a busca de soluções para a formação de bibliotecários mais qualificados.

Nessa direção, embora numerosas, as turmas de 2012 apresentaram desempenho satisfatório. Aqui se destacam os alunos do período noturno. De uma turma com 38 discentes matriculados, 95\% obtiveram aprovação, dos quais $18 \%$ com conceito igual a Excelente, $66 \%$ com Bom, e 11\% com Regular. Por outro lado, tem-se um quantitativo de $5 \%$ de alunos desistentes. Quanto a esses últimos casos, é curioso observar que os desistentes que frequentaram a disciplina em 2012 pertencem a turmas de anos anteriores. Tem sido observado que esses alunos sempre abandonam o curso imediatamente após o resultado da primeira avaliação - tradicionalmente dissertativa -, às vezes antes mesmo de realizá-la. Diante do fato, uma hipótese a ser verificada se refere à ideia de que tais alunos dão prioridade ao estágio remunerado, os quais são abundantes na capital paraense, consequentemente, resultando em prejuízo a um melhor desempenho em sala de aula. Outra hipótese pensada diz respeito aos elementos da subjetividade discente, notadamente da ordem dos afetos, o que talvez funcione como um mecanismo de resistência, seja à disciplina, seja à figura do professor, considerado por alguns como "exigente".

Entre os 38 ingressantes do curso matutino, têm-se, por sua vez, $74 \%$ de aprovação, em que se registram os seguintes conceitos: Excelente, 5\%; Bom, 65\%; e, Regular, 17\%. Como se vê, em termos gerais, dos 198 discentes que cursaram História do Livro e das Bibliotecas entre 2010 e 2012, 92\% foram aprovados, sendo que $27 \%$ obtiveram conceito Excelente, 55\% conceito Bom, e 10\% Regular. 
Enfim, elementos esses que apontam também para o desempenho docente e dos monitores no contexto de uma disciplina que se revela como basilar na formação dos futuros bibliotecários. Não é para menos que após a passagem por História do Livro e das Bibliotecas os alunos seguem por todo o curso (e mesmo após a graduação) se reportando aos conteúdos assimilados, ao vocabulário adquirido e às experiências que viveram dentro e fora da sala de aula.

Tabela 2 - Desempenho das turmas de História do Livro e das Bibliotecas - 2010-2012

\begin{tabular}{|c|c|c|c|c|c|c|c|c|c|c|c|c|c|c|}
\hline \multirow{2}{*}{ Conceitos } & \multicolumn{4}{|c|}{ Turmas 2010} & \multicolumn{4}{|c|}{ Turmas 2011} & \multicolumn{4}{|c|}{ Turmas 2012} & \multicolumn{2}{|c|}{ Conceitos } \\
\hline & Manhã & $\%$ & Noite & $\%$ & Manhã & $\%$ & Noite & $\%$ & Manhã & $\%$ & Noite & $\%$ & Subtotais & $\%$ \\
\hline EXC & 13 & 43 & 7 & 27 & 10 & 32 & 14 & 44 & 2 & 5 & 7 & 18 & 53 & 27 \\
\hline BOM & 17 & 57 & 12 & 46 & 17 & 53 & 13 & 41 & 26 & 65 & 25 & 66 & 110 & 55 \\
\hline REG & - & - & 3 & 11 & 2 & 6 & 3 & 9 & 7 & 17 & 4 & 11 & 19 & 10 \\
\hline INS & - & - & 2 & 8 & 1 & 3 & 1 & 3 & 2 & 5 & - & - & 6 & 3 \\
\hline SF & - & - & 2 & 8 & 2 & 6 & 1 & 3 & 3 & 8 & 2 & 5 & 10 & 5 \\
\hline Totais & 30 & 100 & 26 & 100 & 32 & 100 & 32 & 100 & 40 & 100 & 38 & 100 & 198 & 100 \\
\hline
\end{tabular}

Fonte: Folhas de aproveitamento da disciplina História do Livro e das Bibliotecas, Sistema de Controle Acadêmico - (UFPA, 2009)

\section{CONSIDERAÇÕES FINAIS}

A experiência docente vivenciada na disciplina História do Livro e das Bibliotecas permite destacar fatores críticos e pontos fortes observados entre 2010 e 2012. Entre os de caráter negativo tem-se a dificuldade de envolver um número maior de discentes das turmas noturnas nas visitas técnicas, o que se explica pelo fato de que muitos e muitas trabalham durante o horário comercial, exatamente o período em que também funcionam as bibliotecas visitadas. Nessa direção, seria fundamental que a Seção de Obras Raras da Biblioteca Central da UFPA funcionasse à noite, a fim de tornar possível o contato das turmas noturnas com esse acervo cheio de peculiaridades técnicas e históricas que se relacionam à disciplina e que, por isto, precisam ser vistos pelos alunos do período noturno. 
Outro fator interveniente corresponde à grande oferta de vagas para estágios em Biblioteconomia na cidade de Belém, inclusive aos discentes que estão cursando o primeiro semestre. Alguns chegam a estagiar em duas instituições, o que traz prejuízo ao estudo, na medida em que este passa a ocupar um segundo plano diante da necessidade do autossustento, do sustento familiar, ou, simplesmente, do desejo de consumo. Essa é a realidade que se verifica precisamente entre aqueles que já se matricularam, abandonaram ou reprovaram em História do Livro e das Bibliotecas repetidas vezes, colocando-se como uma dificuldade que se estende também para outras disciplinas ofertadas pela $F A B I B / U F P A$.

Quanto aos aspectos fortes, destacam-se: (1) a melhora na habilidade de escrever, ainda que sejam necessários avanços na leitura, sobretudo na compreensão e na interpretação de textos técnicocientíficos; (2) o interesse pela produção científica, como evidenciou a participação autoral dos recém-ingressos nos eventos na área de Biblioteconomia promovidos por e para estudantes de graduação; (3) o aumento do interesse por cursos de idioma, com destaque para a participação de discentes das turmas de 2012 no Projeto Universia, desenvolvido pela Agência de Inovação Tecnológica da UFPA (UNIVERSITEC); (4) a inclusão, a participação e o envolvimento de monitores na disciplina, algo fundamental no planejamento, na execução e no acompanhamento das atividades propostas para as numerosas turmas de 2012, permitindo que o trabalho docente fosse mais bem conduzido e documentado; e, também (5), a assimilação dos conteúdos trabalhados dentro e fora da sala de aula, o que se reflete ao longo de toda a vida acadêmica dos alunos na universidade. Um aprendizado que certamente será mobilizado na vida profissional, pois o autor deste trabalho também carrega consigo, vivencia e atualiza os conhecimentos com os quais entrou em contato na disciplina História do Livro e das Bibliotecas na condição de aluno de sua hoje companheira de Faculdade, a professora Maria Izabel Moreira Arruda. 


\section{AGRADECIMENTOS}

Aos(às) alunos(as) das turmas de 2010, 2011 e 2012 do curso de Biblioteconomia; à Faculdade de Biblioteconomia (FABIB/UFPA); ao Instituto de Ciências Sociais Aplicadas (ICSA/UFPA); a Orinete Sousa, a Carlos Nascimento e a Diego Barros, monitores competentes na condução auxiliar da disciplina; a Cleide Dantas e a Rita Favacho pelas leituras e contribuições; e à Pró-Reitoria de Ensino de Graduação (PROEG/UFPA). A todos, porque a docência não é trabalho que se faz sozinho, se não com a colaboração de muitos.

\section{REFERÊNCIAS}

ASSMANN, Hugo. Reencantar a educação: rumo à sociedade aprendente: com um glossário de conceitos. Petrópolis: Vozes, 1998.

BARRETO, Aldo de Albuquerque. A condição da informação. São Paulo em Perspectiva, São Paulo, v. 16, n. 3, p. 67-74, 2002. Disponível em: <http://www.aldoibct.bighost.com.br/A\%20Condicao.pdf>. Acesso em: 15 ago. 2013.

A questão da informação. São Paulo em Perspectiva, São Paulo, v. 8, n. 4, p. 3-8, 1994. Disponível em: <http://bogliolo.eci.ufmg.br/downloads/BARRETO\%20A\%20Questao\%2 0da\%20Informacao.pdf>. Acesso em: 15 ago. 2013.

BECKMANN, Clodoaldo F. R. Para a história da UFPA: o ensino da Biblioteconomia. Belém: EDUFPA, 2007.

BRASIL. Decreto n. 6.096, de 24 de abril de 2007. Institui o Programa de Apoio a Planos de Reestruturação e Expansão das Universidades Federais - REUNI. Diário Oficial [da] República Federativa do Brasil, Brasília, D.F., 25 abr. 2007. Disponível em:

<http://www.planalto.gov.br/ccivil_03/_ato2007-

2010/2007/decreto/d6096.htm>. Äcesso em: 16 ago. 2013.

GIL PANEQUE, Cristina. El alto destino de los escribas. Historia y Vida, Madrid, v. 42, n. 507, p. 51-59, jun. 2010.

HATTSTEIN, Markus. Monasteries: places of spirituality and seclusion around the world. New York: Parragon Books, 2010.

LYONS, Martyn. Livro: uma história viva. São Paulo: SENAC, 2011. 
MCNEELY, lan; WOLVERTON, Lisa. A reinvenção do conhecimento: de Alexandria à Internet. Rio de Janeiro: Record, 2013.

MARTINS, Wilson. A palavra escrita: historia do livro, da imprensa e da biblioteca. São Paulo: Ática, 2002.

OLIVEIRA, Roberto Cardoso. O trabalho do antropólogo: olhar, ouvir, escrever. Revista de Antropologia, São Paulo, v. 39, n. 1, p. 13-37, 1996.

SAMAIN, Etienne. "Ver" e "dizer" na tradição etnográfica: Bronislaw Malinowski e a fotografia. Horizontes Antropológicos, Porto Alegre, v. 1, n. 2, p. 23-60, jul./set. 1995.

\title{
UNIVERSIDADE FEDERAL DO PARÁ. Estatuto e Regimento Geral da
} UFPA. Belém: EDUFPA, 2009a.

Projeto pedagógico do curso de biblioteconomia. Belém, 2009b. Disponível em: <http://www.ufpa.br/biblio/arquivos/PPC_Biblioteconomia Completo.pdf>. Acesso em: 2 nov. 2012.

\section{Title}

The teaching experience in the teaching of history of the book and of the libraries at the Universidade Federal do Pará (UFPA)

\begin{abstract}
Introduction: The work reports the teaching experience in the subject History of the Book and of the Libraries of Librarianship course of the Universidade Federal do Pará (UFPA). It presents in the curriculum of the course since 1963, this subject is fundamental to the formation of future librarians, because it works with three important elements that are dynamic in the history of the profession: the support (the book), the institution (the library) and the professional (the librarian).

Objectives: It collects, systematizes and socializes strategies used in the teaching-learning process in the context of the subject History of the Book and of the Libraries.

Methodology: During two years (2010-2012), over expository classes, the teaching - learning process was improved with the achievement of technical visits, introduction of texts for complementary reading in foreign language, and the building of a site with the help of monitors, to associate the technological innovations to a subject which the elements "book" and "library" provoke in the universitarians the idea of tradition.

Results: The used strategy shows to be satisfactory as to the performance of the students. The main challenge is in the necessity of development of the skills of reading and writing, essential aspects to be considered to the qualitative professional training, especially because the future graduated people will act in the documentation/information field.
\end{abstract}


Conclusions: The negative aspects of the experience: (1) the difficulties of the students in evening classes to participate of technical visits; and (2) the accumulated stages by students that affect performance in the course. The positive aspects of the experience: (1) the improvement of writing skills; (2) the growth of interest by scientific production; (3) the growth of interest in language courses; (4) the contact of class monitors with the teaching practice; and (5) a better assimilation of the contents worked in the subject.

Keywords: Higher education. Librarianship. History of the book and of the libraries. Universidade Federal do Pará. College of librarianship.

\section{Titulo}

La experiencia docente en la enseñanza de la historia del libro y de las bibliotecas en la Universidade Federal do Pará (UFPA)

\section{Resumen}

Introducción: El trabajo reporta la experiencia de la enseñanza en la disciplina Historia del Libro y de las Bibliotecas en el curso de Biblioteconomía de la Universidade Federal do Pará (UFPA). Presente en el currículo del curso desde 1963, esta disciplina es fundamental para la formación de los bibliotecarios futuros, ya que trabaja con tres elementos importantes que son dinámicos en la historia de la profesión: el soporte (el libro), la institución (la biblioteca) y el profesional (el bibliotecario).

Objetivo: Recopila, sistematiza y socializa estrategias utilizadas en el proceso de enseñanza-aprendizaje en el contexto de la disciplina Historia del Libro y de las Bibliotecas.

Metodología: Durante dos años (2010-2012), más allá de las clases orales, el proceso de enseñanza-aprendizaje se agilizó con visitas técnicas, introducción de textos para la lectura en idioma extranjero y la construcción de un sitio web, con la ayuda de monitores, con el fin de asociar las nuevas tecnologías a una disciplina en que los elementos "libro" y "biblioteca" sugieren la idea de tradición a los estudiantes.

Resultados: La estrategia utilizada ha resultado en desempeño satisfactorio de los estudiantes. El principal desafío es la necesidad de desarrollar las habilidades de lectura y de escritura, aspectos esenciales a tener en cuenta para la formación cualitativa, sobre todo porque los futuros graduados trabajarán en el área de la documentación/información.

Conclusiones: Los aspectos negativos de la experiencia: (1) las dificultades de los estudiantes de clases nocturnas para participar en visitas técnicas; y (2) las pasantías acumuladas por los estudiantes que afectan el rendimiento en el curso. Los aspectos positivos de la experiencia: (1) la mejora de las habilidades de escritura; (2) el crecimiento del interés en la producción científica; (3) el creciente interés en los cursos de idiomas; (4) el contacto de los monitores de clase con la práctica docente; y (5) una mejor asimilación de los contenidos trabajados en la disciplina.

Palabras clave: Educación superior. Biblioteconomía. Historia del Libro y de las Bibliotecas. Universidade Federal de Pará. Facultad de Biblioteconomía.

Recebido em: 24.02.2014

Aceito em: 31.07.2015 